\title{
Nutritional Support of Dogs and Cats after Surgery or Illness
}

\author{
Ronald J. Corbee ${ }^{*}$, Wim J. S. Van Kerkhoven ${ }^{2}$ \\ ${ }^{1}$ Department of Clinical Sciences of Companion Animals, Faculty of Veterinary Medicine, Utrecht University, \\ Yalelaan, Utrecht, The Netherlands \\ ${ }^{2}$ Viyo International NV, ljzerenpoortkaai 3, Antwerpen, Belgium \\ Email: ${ }^{*}$ R.J.Corbee@uu.nl
}

Received 24 February 2014; revised 20 March 2014; accepted 27 March 2014

Copyright (C) 2014 by authors and Scientific Research Publishing Inc.

This work is licensed under the Creative Commons Attribution International License (CC BY). http://creativecommons.org/licenses/by/4.0/

(C) (i) Open Access

\begin{abstract}
Nutritional support early during the postoperative period or after onset of illness decreases the mortality rate and shortens the duration of hospitalization of dogs and cats. The preferred feeding route is dependent on the condition of the patient. If there are no contraindications, every patient must receive nutritional support, at least consistent with the resting energy requirement (RER). Several nutrients may be beneficial during healing and recovery from illness or surgery, but further research is needed to empirically certify the effects of these nutrients in critically ill patients.
\end{abstract}

\section{Keywords}

Recovery, Food Supplementation, Nutrition, Nutraceuticals

\section{Introduction}

Nutritional support is important for animals during recovery from illness or surgery. Many animals will recover from mild illness or standard surgical procedures at home, but patients with more severe disease or conditions will be hospitalized during recovery. It is recommended to have a protocol for nutritional support of hospitalized patients since early nutritional support has been reported to improve outcome and to shorten hospitalization time in humans [1] [2] and dogs [3]. Proper absorption of fluids, energy, and essential nutrients is of primary importance during the first 14 days after trauma or onset of illness [4]. It is important to provide nutrients to an animal recovering from illness or surgery to ensure optimal functioning of the gastrointestinal and immune systems. Enteral feeding is preferable to parenteral feeding because intraluminal agents stimulate the gastrointestinal tract and prevent bacterial translocation [4].

"Corresponding author. 
In the present paper we review the current knowledge regarding mechanisms involved in impaired food absorption after surgery or during serious illness, and propose a solution to restore these unfavorable mechanisms.

\section{Hypometabolism versus Hypermetabolism}

A healthy animal that has insufficient food available will gradually adapt its metabolism to that situation. Once glycogen stores are exhausted (typically 24 to 48 hours after cessation of food intake) the body will primarily draw on fat reserves. Proteins will also be broken down to meet energy requirements; this may begin within 2 hours but is most dramatic after 2 weeks of a total lack of food intake [5]. The metabolic rate slows down in these conditions as a result of a decrease in the conversion of thyroxine into triiodothyronine (insulin-dependent event), which allows the animal to conserve available energy [6] [7]. This state can be termed hypometabolism.

Stress response is the term for the hormonal and metabolic changes in an animal after illness, trauma, or surgery. Stress results in activation of the sympathetic nervous system, which results in alterations to the endocrine system, primarily insulin resistance and changes in secretion of pituitary gland hormones [8] [9] (Table 1). In addition, there are immunologic (production of cytokines and acute-phase reaction) and hematologic (neutrophilia and lymphocyte proliferation) changes [8] (Table 2).

In human medicine, it requires an average of 14 days for optimal recovery after illness or a surgical procedure. This 14-day recovery period can be categorized into 2 phases of metabolic alterations. Phase 1 of recovery is the first 24 to 48 hours of the recovery period. During this time, fluid therapy and the provision of nutrients to the intestinal tract are important [10] [11]. The second phase of recovery begins after day 3 . This period includes the need for increased calorie administration; thus, the need for nutritional support is often stressed for patients after 3 days of malnutrition [12]. It has been suggested, [13] but not proven, that timely nutritional support with nutrients such as arginine, glutamine, taurine, long-chain polyunsaturated omega- 3 fatty acids, and prebiotics can shorten the recovery period of cats and dogs after illness or surgery.

Table 1. Endocrine and hormonal reactions after a surgical procedure.

\begin{tabular}{|c|c|c|}
\hline Endocrine gland & Hormones & Changes in secretion \\
\hline Anterior pituitary & $\begin{array}{l}\text { ACTH* } \\
\text { Growth hormone } \\
\text { TSH } \\
\text { FSH and LH }\end{array}$ & $\begin{array}{l}\text { Elevated } \\
\text { Elevated } \\
\text { Can be elevated or lowered } \\
\text { Can be elevated or lowered }\end{array}$ \\
\hline Posterior pituitary & AVP & Elevated \\
\hline Adrenal cortex & $\begin{array}{l}\text { Cortisol } \\
\text { Aldosterone }\end{array}$ & $\begin{array}{l}\text { Elevated } \\
\text { Elevated }\end{array}$ \\
\hline Pancreas & Insulin & Elevated \\
\hline Thyroid & Thyroxine, triiodothyronine & Lowered \\
\hline
\end{tabular}

*ACTH, adrenocorticotropic hormone (corticotropin); AVP, arginine vasopressin; FSH, follicle stimulating hormone; LH, luteinising hormone; TSH, thyroid stimulating hormone; Based on Desborough and Hall. Stress response after surgery is characterized by an increased secretion of pituitary hormones and by an activation of the sympathetic nervous system. These changes in pituitary secretion have a secondary effect on the hormonal secretion of the affected organs. These so-called target-organs and their hormonal changes are mentioned in this table. (Adapted from Desborough JP, Hall GM. Endocrine response to surgery. Anesth Rev 1993; 10:131-148. Reprinted with permission).

Table 2. Systemic reactions after a surgical procedure.

Sympathetic nervous system activation

Endocrine stress response

Pituitary hormone secretion

Insulin resistance

Cytokin production

Acute phase reaction

Immunological and hematological changes

Neutrophil leucocytosis

Lymphocytes proliferation

Stress response is the name given to the hormonal and metabolic changes occurring after injury or trauma. It's part of a systemic wound reaction and comprises a wide range of endocrine, immunological and hematological changes. This table focuses on the systemic reactions that occur after surgery. (Adapted from Desborough J.P. The stress response to trauma and surgery; British Journal of Anaesthesia 2000; 85: 109-117. Reprinted with permission). 
In general, phase 1 begins during surgery and lasts for 24 to 48 hours after surgery. Even before an animal awakes from anesthesia, vital needs must be met. Therefore, because the body must function with less energy and less oxygen, the relative metabolic rate, cardiac flow, and oxygen consumption are reduced (Figure 1). During phase 1, it is the maintenance of the circulation of bodily fluids through transfusion or other means that is of foremost importance, rather than the supply of energy. It is important during this phase that the intestines be provided with nutrients and fluids because of reduced blood flow through the gastrointestinal tract owing to the release of cortisol and catecholamines [8] [10] [11]. Phase 1 should focus on having an animal eat and drink as soon as possible after surgery [8].

Next comes phase 2 and its energy requirement, in which metabolic rate, nitrogen excretion, and oxygen consumption are increased. Supplying alimentation in line with the severity of the invasiveness of the surgery becomes important when transitioning from phase 1 to phase 2 [8] [10] [11]. During phase 2, the goal is to provide an animal with sufficient energy (calories) (Table 3).

However, enteral feeding is not recommended when there is excessive hemorrhage into the gastrointestinal tract; a volvulus, severe constipation, or any other gastrointestinal tract blockage; or excessive vomiting [14]

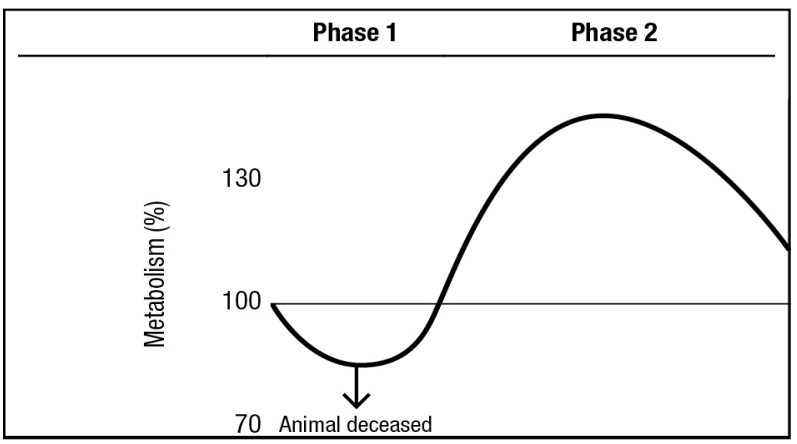

\begin{tabular}{|lcc|}
\hline & Phase 1 & Phase 2 \\
\hline Blood sugar concentration & $\uparrow$ & $\uparrow$ \\
Body temperature & $\downarrow$ & $\uparrow$ \\
Cardiac flow & $\downarrow$ & $\uparrow$ \\
Free fatty acids & $\uparrow$ & $\uparrow$ \\
Gluconeogenesis & $\uparrow$ & $\uparrow$ \\
Insulin & $\downarrow$ & $\uparrow$ \\
Insulin resistance & $\uparrow$ & $\uparrow$ \\
Lipolysis & $\uparrow$ & $\uparrow$ \\
Nitrogen balance & - & $\downarrow$ \\
Oxygen consumption & $\downarrow$ & $\uparrow$ \\
Protein degradation & - & $\uparrow$ \\
Stress hormones & & $\uparrow$ \\
(catecholamine, glucagon & $\uparrow$ & \\
and cortisol) & & \\
\hline
\end{tabular}

Phase 1 is the first 24 to 48 hours of the recovery period during which the body must function with less energy and less oxygen; thus, the relative metabolic rate, cardiac flow, and oxygen consumption are reduced. Phase 2 of recovery begins on approximately day 3 and lasts until approximately day 14 after surgery. During phase 2, the metabolic rate, nitrogen excretion, and oxygen consumption are increased. $\uparrow=$ Increased. $\downarrow=$ Decreased. $-=$ No change (Adapted from: Otani J. Feeding tube practices before and after gastrointestinal surgery. Infusion Therapy News 2003; 3 - 5. Yoshikawa K. Feeding tube techniques and carbohydrate metabolism Journal of clinical and experimental medicine-special issue: 9-14, (1996). Reprinted with permission).

Figure 1. Changes in metabolism after a surgical procedure (top) and alterations in various factors (bottom). 
Table 3. 2-phase system.

\begin{tabular}{|c|c|c|}
\hline Recuperation phase & Support & Recuperation time \\
\hline $\begin{array}{c}\text { Phase } 1 \\
\text { (critical start-up) } \\
0 \mathrm{~h}-48 \mathrm{~h}\end{array}$ & $\begin{array}{l}\text { Pet needs to be stimulated to eat: feed the gut } \\
\text { (immune function stimulation) } \\
+ \text { intake of water + all essential } \\
\text { recuperation nutrients. }\end{array}$ & Average 14 days \\
\hline $\begin{array}{l}\text { Phase } 2 \text { (Follow-up) } \\
\text { From day } 3\end{array}$ & $\begin{array}{c}\text { Arginine, Taurine, L-Glutamine, } \\
\text { Omega } 6 \text { \& } 3 \text { fatty acids + Normal diet } \\
\text { (Energy) }\end{array}$ & \\
\hline
\end{tabular}

The animal needs an average of 14 days for an optimal recovery after illness or a surgical procedure. These 14 days are divided in 2 phases. During phase 2 the goal is to provide the animal with sufficient energy (calories), phase 1 focusses on having the animal eat and drink again as soon as possible and deliver the so-called recuperation nutrients: glutamine, taurine, arginine and omega $6 \& 3$ fatty acids. For an optimal recovery these recuperation nutrients will also have to be provided during phase 2 and so for 14 days.

[15]. In these situations, the patient should be stabilized and then should receive parenteral nutritional support.

A state of hyper-metabolism exists during phase 2 [10] [11] [16]. Because of the effects of inflammatory cytokines in the catabolic state; protein will be catabolized (for energy and gluconeogenesis), used for the synthesis of acute-phase proteins and immunoglobulins, and needed for wound healing. Given this hyper-metabolic state, it is important for early nutritional support to provide energy and protein to promote recovery. It is also essential to consider the supplementation of recovery nutrients because many foods are deficient in energy and protein, compared with the amounts of those nutrients required for optimal recovery [10] [11]. Nutritional support (arginine, taurine, l-glutamine, omega-6 fatty acids, and omega-3 fatty acids) for at least 3 days is generally needed to change from a catabolic to an anabolic state. Subsequent adaptation to full recovery may require several weeks. During phase 2, there continues to be an increased need for protein (> $12 \mathrm{~g} / \mathrm{MJ}$ of ME [> $5 \mathrm{~g} / 100$ $\mathrm{kcal}$ of ME] in dogs and $>18 \mathrm{~g} / \mathrm{MJ}$ of ME [ $>7.5 \mathrm{~g} / 100 \mathrm{kcal}$ of ME] in cats) and fat ( $>12 \mathrm{~g} / \mathrm{MJ}$ of ME [ $>5 \mathrm{~g} / 100$ $\mathrm{kcal}$ of ME], unless fat restriction is desired (4.8 to $8.4 \mathrm{~g} / \mathrm{MJ}$ of ME [2.0 to $3.5 \mathrm{~g} / 100 \mathrm{kcal}$ of ME) [7].

\section{Anorexia versus Hyporexia}

Sick animals often ingest an insufficient amount of nutrients because of the primary disease or because of admission to a clinic (e.g. change in diet or feeding routine). Before nutritional support is initiated, a patient must be hemodynamically stable and have adequate pain relief. In addition, clinicians should distinguish between anorexia and hyporexia. Hyporexia refers to a decreased appetite, rather than a total loss of appetite [14]. In the case of anorexia, forced feeding will not stimulate spontaneous food intake. However, enteral feeding or parenteral feeding should be provided to anorectic patients [5] [17]. It should be mentioned that treating the underlying disease also contributes to improving spontaneous food intake.

For hyporectic patients, stimulation of spontaneous food intake may be sufficient and diminishes the need for other assisted feeding techniques, which are more invasive and stressful. This should not lead to a one-more-day syndrome during which nutritional support is not initiated because of the expectancy that an animal will starteating at some point (e.g. the next day). If stimulation of spontaneous food intake results in an insufficient effect (i.e. does not result in an adequate amount of food intake) during phase 1, other assisted feeding techniques should be implemented to ensure the administration of sufficient amounts of nutrients during phase 2 .

\section{Cachexia and Sarcopenia}

Cachexia has been defined as loss of lean body mass. Cachexia affects a large proportion of dogs and cats with congestive heart failure, chronic kidney disease, cancer, and a variety of other chronic diseases. By contrast, sarcopenia is loss of lean body mass that occurs with aging in the absence of disease. Both conditions are associated with increases in morbidity and mortality rates [18]. Fat is the predominant fuel source in healthy, anorectic dogs and cats, whereas cachectic dogs and cats use both fat and amino acids as fuel sources. This latter situation contributes to loss of lean body mass and possible decreases in immune function, wound healing, and survival rate. Nutritional assessment guidelines [19] have been formulated that include methods for early detection of muscle mass to enable clinicians to take preventive measures for animals in a pre-cachectic state. During the 
catabolic or hyper-metabolic recovery phase, feeding patients foods with increased energy density and increased protein concentration will help prevent additional loss of lean body mass.

\section{Importance of Nutritional Support for Wound Healing and Fighting Infection}

It is vital that animals begin to eat and drink as soon as possible during the first 48 hours after trauma, surgery, or illness. Malnutrition leads to an increased mortality rate in humans because of decreasing potassium, phosphorus, and magnesium concentrations and reductions in immune function [1] [2]. Food intake provides nutrients (amino acids, fatty acids, vitamins, and minerals) that help optimize the immune response, tissue repair, and tissue synthesis as well as the metabolism of administered medications [1]-[3]. One problem that often arises is that patients refuse to eat during phase 1, usually as a consequence of catabolic stress. Almost all hospitalized animals have a negative energy balance, and almost half of the animals have that negative energy balance as a result of food refusal [20]. Animals in negative energy balance have a deficit of essential nutrients. As a consequence, palatability of nutritional products that promote recovery must be extremely high because the appetite of nearly all animals is dramatically reduced during the recovery [21]-[25].

In addition, an optimally functioning immune system is crucial for recovery from illness and after surgery. It has been estimated that approximately $60 \%$ to $70 \%$ of the immune system function of cats and dogs is in the intestines; therefore, the intestinal structure (mucosa) must remain intact for proper immune development [15]. As mentioned previously, the first 14 days are typically extremely important, especially for the ingestion of fluids and essential nutrients via enteral alimentation. As such, nutrients ingested during this period promote optimal gastrointestinal tract function.

\section{Bacterial Translocation}

Bacterial translocation is a phenomenon in which intestinal bacteria migrate from the intestines through the intestinal wall into the mesenteric lymph nodes and internal organs where they are not typically found. Surgical procedures can be associated with unexpected inflammation, serious infections, and resultant compromised organ function [1]-[4]. One possible cause is bacterial translocation (causing gastrointestinal tract-associated sepsis), and this phenomenon may be attributable to 1 or several causes. Malnutrition of the gastrointestinal tract (i.e. the gastrointestinal tract is deprived of intraluminal nutrients) decreases cell turnover and mucosal mucus production, which thereby decreases the barrier function and surface of the gastrointestinal tract and results in malabsorption of nutrients. The synthesis of immunoglobulins is often also decreased because of protein malnutrition, thus decreasing gastrointestinal tract-barrier function (gastrointestinal tract-associated lymphoid tissue) [26]. Therefore, support of the gastrointestinal tract with intraluminal nutrients will be beneficial in all anorectic animals.

The absence of intraluminal nutrients also reduces blood flow to the gastrointestinal tract. Parenteral nutrition does not deliver intraluminal nutrients and thus might predispose an animal to bacterial translocation. The postsurgical mortality rate decreased in laboratory rats with artificially induced peritonitis when the rats received enteral nutrition, compared with the mortality rate when rats received parenteral nutrition (Table 4) [27]. Several studies [4] [27]-[29] in humans have found that there are fewer (20\% less) infections after surgery when enteral (peroral) feeding is used, as opposed to the number of infections after surgery when parenteral (IV) feeding is used. Furthermore, enteral feeding soon after surgery supports recovery of gastrointestinal tract motility and improvement of the general condition in humans [28]. It is likely that there may be a similar situation in veteri nary practice. Reduced blood flow to the gastrointestinal tract provokes damage to the epithelial cells and there

Table 4. Chances of postoperative survival for different forms of food administration in laboratory rats after laparotomy.

\begin{tabular}{ccc}
\hline & $\mathbf{N}^{*}$ & Survival rate (\%) \\
\hline Oral feeding & 15 & 80.0 \\
Enteral (tube) feeding & 13 & 61.5 \\
Intravenous feeding & 10 & 20.0 \\
\hline
\end{tabular}

$* \mathrm{~N}=$ number of animals in treatment (Adapted from Fukushima R. Counteraction against bacterial translocation (1) the nutrient canal. $J$ Jpn Surg Soc 2007; 108: 206-210. Reprinted with permission). 
fore increases permeability of the gastrointestinal tract [17]. Bacterial overgrowth, inflammatory bowel disease, and other gastrointestinal diseases cause a loss of barrier function and therefore are possible causes of bacterial translocation. Bacterial translocation has been detected in cats [30] and humans [31] [32]; however, bacterial translocation has not been proven in dogs with pancreatitis [33] [34]. Damage to the gastrointestinal tract is usually associated with bacterial translocation [30] [35]. A study [36] in dogs with gastric dilatation-volvulus revealed no bacterial translocation; however, bacterial translocation can occur in dogs and cats when the mucosal barrier is damaged by an underlying disease or by treatment with medications (e.g. chemotherapeutics, immunosuppressive drugs, and certain antimicrobials) that influence the gastrointestinal barrier and gastrointestinal tract motility [30] [37]. It should be mentioned that bacterial translocation does not occur when food is withheld from healthy dogs or healthy dogs are fed parenterally [38]. Most dogs and cats with an underlying illness are anorectic. A nonfunctional gastrointestinal tract is an indication for parenteral feeding, and animals with a nonfunctional gastrointestinal tract are especially at risk for bacterial translocation.

Investigators in 1 study [14] compared early-stage enteral nutrition and total parenteral nutrition with regard to the improvement of the nitrogen balance in humans after surgery for esophageal cancer. Those investigators found that it required 8 days after surgery for the nitrogen balance to normalize when enteral nutrition was provided, whereas it required 14 days after surgery for the nitrogen balance to normalize when parenteral nutrition was provided (Figure 2) [16]. It appears that there is a similar time frame for domestic animals [39] [40].

\section{Stimulation of Spontaneous Food Intake}

Spontaneous food intake is a sign of recovery, so it is important to offer food and to stimulate spontaneous food intake daily to monitor return of appetite. Hospitalization often is a stressful event for an animal; thus, it is important to recreate an animal's home environment as much as possible during hospitalization to encourage spontaneous food intake. A calm and relaxed atmosphere, appropriate and tender care, and a light cycle (No. of hours of light vs No. of hours of darkness) consistent with the time of year will provide ideal conditions for encouraging feed intake. Some medications, including opiates, antimicrobials, diuretics, immunosuppressives, and chemotherapeutics, can have inhibitory effects on food intake [41]. It is often preferable to initially provide a hospitalized animal with the food that it typically receives at home, rather than immediately feeding it the diet that will eventually be prescribed. This is certainly the case for animals with neophobia (suspicion of unknown foods). In our experience, aversion to diets administered during hospitalization is common, and this makes it more difficult to change to therapeutic diets. Furthermore, the authors do not recommend offering several foods at the same time.

A palatable food increases the chances of spontaneous food intake. Most critical care diets $[A, B, C]$ are extremely flavorful. In addition, food can be made more attractive by increasing the moisture content. Higher

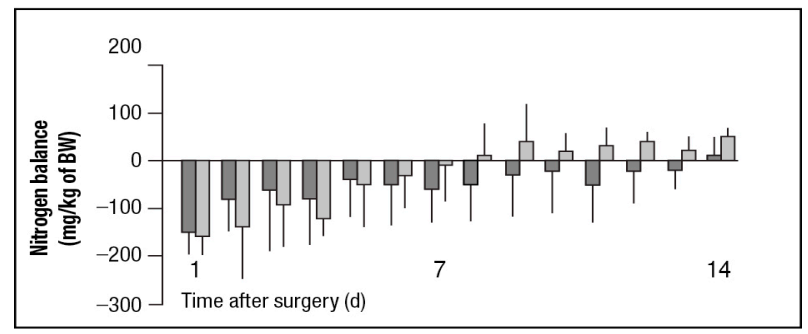

Mean \pm SD nitrogen balance in humans receiving nutrients via total parenteral nutrition (dark gray bars; $\mathrm{n}=30$ ) or enteral feeding (light gray bars; 20) after surgery. Notice that the postoperative nitrogen balance was better for enteral feeding than for parenteral feeding. BW = Body weight. A study compared the use of enteral feeding in an early stage with total parenteral feeding in order to improve the nitrogen balance in humans after a surgical procedure in case of an esophageal cancer. It was proven that the nitrogen balance is normalized after 8 days post-surgery in case of enteral feeding. 14 days were needed in case of total parenteral feeding (Adapted from Omata J, Fukatsu K, Maeshima Y, et al. Enteral nutrition rapidly reverses total parenteral nutrition-induced impairment. Clin Nutr 2009; 28: 668-673. Reprinted with permission).

Figure 2. Postoperative nitrogen balance for different forms of food administration in humans. 
moisture content also contributes to rehydration of patients and causes the nutrients to leave the stomach more quickly, making it less likely that the food will be vomited or regurgitated [42]. Canned foods have high moisture content and often higher fat and protein contents, which also enhance palatability. However, foods with a high fat content will slow down gastric emptying [42]. Still, such foods are often preferred, unless there are contraindications for a high fat or protein content.

Cats are often strongly attached to the texture of food. If cats were fed dry food since they were kittens, the chances are they will spontaneously eat dry food rather than canned alternatives. Adding sugar can improve the flavor of dog food, but cats have no taste receptors for sweetness [43]. Artificial sugars (e.g. xylitol) can lead to hypoglycemia in cats and dogs and should be avoided [17].

Heating food to body temperature also has a positive impact on food intake, as does offering fresh food. Food that is not eaten within a short period after it is provided will likely not be eaten later by that an animal. Spontaneous food intake can be encouraged by the addition of water or meat stock to dry food, thereby releasing appetizing aromas.

Appetite-enhancing drugs such as cyproheptadine, mirtazapine, corticosteroids, and diazepam can be used; however, the authors do not recommend the use of these products in hospitalized patients because of their adverse effects. A product [D] has recently been marketed that stimulates the appetite of patients with hyporexia. That product contains flavoring agents as well as nutraceuticals and may be provided to hyporectic and anorectic animals via enteral feeding.

\section{Feeding Methods}

It is important to provide nutrients through the most natural route. Enteral provision of nutrients is preferred to parenteral provision of nutrients. The structure of intestinal villi was compared in rats after enteral and parenteral feeding for 14 days [15] [26] [27]. These studies revealed that there was atrophy of the intestinal villi within 3 days after onset of total parenteral nutrition. The villi of the small intestine became smaller and thinner, and the enzymatic activity decrease. In contrast, the intestinal mucosa structure was maintained in rats provided parenteral nutrition (Figure 3). However, when spontaneous food intake is not successful stimulated, tube feeding or parenteral nutrition should be initiated immediately.

Nutritional support should be administered in accordance with the RER of an animal on the basis of the current body weight. The RER can be calculated by use of the following equations: RER $=(\text { body weight in } \mathrm{kg})^{0.75} \times$ $293 \mathrm{~kJ}$ of ME/d and RER = (body weight in $\mathrm{kg})^{0.75} \times 70 \mathrm{kcal}$ of ME/d. The volume of food should be attained gradually over a period of 2 to 4 days. Should an animal not voluntary consume the necessary volume of food (e.g. poor appetite or condition that prevents eating), then tube feeding should be initiated. Parenteral feeding is indicated for a nonfunctional gastrointestinal tract, the inability to place an enteral feeding tube, or excessive vomiting. Parenteral feeding requires an intensive care setting, and the preparation and handling of products used for parenteral feed should be performed under strict aseptic conditions. Additional information about enter

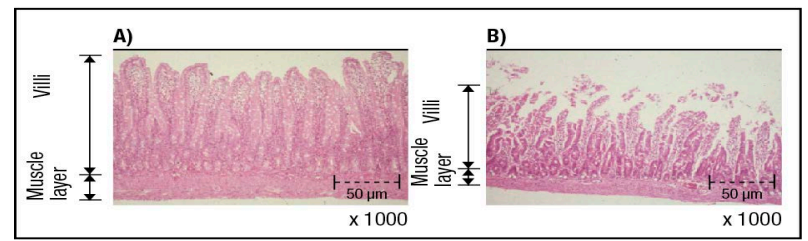

Photomicrographs of tissue sections of the small intestines obtained from rats fed grain for 14 days (A) or provided nutrients via total parenteral nutrition for 14 days (B). Notice that the intestinal villi atrophy and are smaller and thinner in rats after 14 days of total parenteral nutrition. Hematoxylin and Eosin stain; bar $=50 \mu \mathrm{m}$. A study in rats showed that villus atrophy occurred after parenteral feeding. The same study proved that within 3 days after parenteral feeding intestinal villi in the small intestine became thinner and smaller and that there was a decreased enzymatic activity. Conclusion is that parenteral feeding caused a negative effect on the structure of the intestinal mucosa (Adapted from Okuma T. Clinical nutrition in keywords: enteral tube feeding, in Proceedings. Nutr Soc 2007; 66: 299-306. Reprinted with permission).

Figure 3. The structure of intestinal villi in the rat after 14 days grain feeding versus parenteral feeding in laboratory rats. 
al and parenteral feeding techniques have been reported elsewhere [5] [13] [41].

\section{Nutritional Support during Recovery}

As mentioned previously, timely nutritional support with nutrients such as arginine, glutamine, taurine, longchain polyunsaturated omega-3 fatty acids, and prebiotics may possibly shorten the recovery period of cats and dogs after illness or surgery. Thus, it is important to provide these nutrients to hospitalized animals.

\section{Amino acids}

In humans, arginine at a dose of $1.12 \mathrm{~g} / \mathrm{MJ}$ of ME $(0.47 \mathrm{~g} / 100 \mathrm{kcal}$ of ME) enhances the T-cell response and increases the number of T-helper cells in trauma (including surgery) and infection [44] [45]. The mean dose in critical care diets for dogs and cats is 1.20 to $1.77 \mathrm{~g} / \mathrm{MJ}$ of ME (0.50 to $0.74 \mathrm{~g} / 100 \mathrm{kcal}$ of ME). Arginine promotes nitrogen retention, protein turnover, conversion of ammonia to urea, and wound healing [46]. Rats receiving supplemental arginine have an increased ability to synthesize acute-phase proteins [47] and improved rates of wound healing, nitrogen retention, and growth [48] [49]. Investigators in another study [50] on rats found effects of arginine supplementation on recovery of damage to the intestinal tract as well as prevention of bacterial translocation. Arginine improves cardiac output and blood flow through the gastrointestinal tract via increased production of nitric oxide; such improvements result in better wound healing [51]. Arginine is an essential amino acid for dogs and cats. The dietary arginine concentration should be sufficiently high ( $>0.46 \mathrm{~g} / \mathrm{MJ}$ of $\mathrm{ME}$ ) for parenteral feeding, and many human products do not contain that amount of arginine [15].

Glutamine is one of the most important amino acids. It supports health of intestinal cells and improves immunity [52]. However, glutamine is not fully synthesized in stressed animals, including stress induced by surgery [53]. Glutamine supports intestinal activity and the immune system by stimulating the synthesis of specific acute-phase proteins and shortens the recovery period after surgery. Rapidly dividing cells (eg, fibroblasts, lymphocytes, and intestinal epithelial cells) have high glutaminase activity and therefore metabolize much of the available glutamine. Glutamine also serves as the fuel for enterocytes, and it enhances insulin sensitivity by increasing plasma concentrations of glucagon-like peptide-1 [54]. Glutamine also contributes to the synthesis of glutathione (a crucial antioxidant in the gastrointestinal mucosa), aids in the prevention of bacterial translocation, and improves function of the gastrointestinal tract and systemic immune system [50]. Glutamine also enhances de novo synthesis of arginine in the kidneys via the citrulline pathway [55]. Numerous studies [56]-[62], [E] have indicated the effect of glutamine on wound healing and repair. To the authors' knowledge, the specific effective dose for dogs and cats has not been determined; however, $>1.2 \mathrm{~g} / \mathrm{MJ}$ of ME (>0.5 g/100 kcal of ME) is supported [58]. Typical critical care diets contain glutamine at a dose of $2.65 \mathrm{~g} / \mathrm{MJ}$ of ME (1.11 g/100 kcal of ME).

Taurine promotes the healthy development and function of the immune system [63]. Taurine helps fight cellular attack from oxidative stress and plays a major role in bile conjugation, retinal function, and energy metabolism of the myocardium. Taurine is also involved in calcium exchange mechanisms [63] [64] and reduces blood pressure in humans [65]. Taurine deficiency causes dilatative cardiomyopathy in cats and dogs [66]. To the authors' knowledge, the specific effective dose of taurine for prevention of disease in dogs and cats has not been determined. Typical critical care diets contain taurine at doses of $0.30 \mathrm{~g} / \mathrm{MJ}$ of ME $(0.13 \mathrm{~g} / 100 \mathrm{kcal}$ of ME).

\section{Fatty acids}

The use of EPA and DHA offers potential health benefits. Not all omega-3 long-chain polyunsaturated fatty acids are as effective as EPA and DHA, so it is important to know the concentration of EPA and DHA in product that contain omega-3 fatty acids. In addition, those products should contain adequate amounts of antioxidants. Typically, the use of cod liver oil is not recommended because some of those preparations also contain high amounts of vitamins A and D. Furthermore, the products should not be contaminated with heavy metals (eg, mercury). [67] Eicosapentaenoic acid and DHA exert anti-inflammatory effects by altering eicosanoid synthesis and cytokine expression and reducing the expression of tumor necrosis factor- and interleukin 1, which play major roles in anorexia and cachexia. They also contribute to a decrease in the production of leukotriene $\mathrm{B}_{4}$ and prostaglandin $E_{2}$, which play important roles in inflammation and pain. Mitigating pain and inflammation will improve recovery time and accelerate the healing process [68] [69]. Omega-3 fatty acids decrease muscle loss in dogs with chronic heart failure and improve appetite [70]. Omega-3 fatty acids also are beneficial in animals with atopic dermatitis, [71] osteoarthritis, [72] [73] cancer, [74] errors in lipid metabolism, [75] cardiac disease, [76] [77] kidney disease, [78] and ulcerative colitis [79]. The therapeutic use of long-chain omega-3 fatty acids 
and fish oils has recently been reviewed [80]. Dosage recommendations for some clinical conditions range from 0.25 to $0.66 \mathrm{~g}$ of EPA and DHA/MJ of ME ( 0.10 to $0.28 \mathrm{~g} / 100 \mathrm{kcal}$ of ME) for dogs and 0.25 to $1.81 \mathrm{~g}$ of EPA and DHA/MJ of ME (0.10 to $0.76 \mathrm{~g} / 100 \mathrm{kcal}$ of ME) for cats [80]. Typical critical care diets contain 0.42 to $1.41 \mathrm{~g}$ of EPA and DHA/MJ of ME (0.18 to $0.59 \mathrm{~g} / 100 \mathrm{kcal}$ of ME). Because of possible adverse effects of EPA and DHA on blood clotting, EPA and DHA should not be used in patients with coagulation problems [80]. Currently, there is no evidence to support the use of EPA and DHA in all hospitalized patients. Further research is needed on the use of omega-3 fatty acids in hospitalized patients.

\section{Prebiotics}

Prebiotics such as inulin and fructo-oligosaccharides are believed to contribute to health of the gastrointestinal tract. Prebiotics are non-digestible food ingredients that selectively stimulate the growth and activity of 1 or more types of bacteria (including Bifidobacterium spp and Lactobacillus spp) in the colon, thereby improving health of the animal [81]. Fermentation of prebiotics causes a decrease in the $\mathrm{pH}$ in the colonic contents, which promotes growth of probiotic bacteria; the decrease in $\mathrm{pH}$ also has antimicrobial effects on pathogens. Major effects are improvements in bowel function, increases in mineral absorption, alterations in lipid metabolism, reductions in ammonia absorption, and decreases in insulin concentrations [82].

Prebiotics may be beneficial for the management or prevention of diarrhea in hospitalized patients that are receiving medications. Diarrhea is a frequent adverse effect of many medications, including NSAIDs, digitalis, thyroid gland hormones, magnesium-containing compounds, lactulose, anthelmintics, chemotherapeutics, topical insecticides, and antimicrobials. The most common adverse effect of orally administered antimicrobials is a change in the population of intestinal microflora (bacteria and yeast) that typically coexist in a beneficial balance in the gastrointestinal tract. This problem is also evident with parenterally administered antimicrobials. Depending on the antimicrobial used, there may be overgrowth of certain types of organisms, whereas other types of organisms may be suppressed or eliminated. One result of this imbalance can be diarrhea. A well-balanced intestinal flora creates a barrier that prevents the intrusion of harmful bacteria, promotes the transit of food through the intestines, stimulates the immune system, neutralizes the production of harmful elements, and ferments non-digestible fiber to form valuable short-chain fatty acids (e.g. butyric acid). These short-chain fatty acids are used as a substrate by colonocytes to maintain the integrity of the gastrointestinal tract, facilitate the absorption of water and electrolytes, and thus minimize the risk of diarrhea. Short-chain fatty acids are a subgroup of fatty acids that have fewer than 6 carbon atoms. They include acetic acid, propionic acid, isobutyric acid, butyric acid, isovaleric acid, valeric acid, caproic acid, lactic acid, and succinic acid. Similar to mediumchain fatty acids, short-chain fatty acids are transported directly into the portal vein during lipid digestion. This is in contrast to long-chain fatty acids, which are packaged into chylomicrons and enter lymphatic capillaries before being admixed with blood in the subclavian vein [83]. Therefore, short-chain fatty acids are readily absorbed by colonocytes. To the authors' knowledge, the specific effective dose of prebiotics for dogs and cats has not been determined. It has been suggested [84]-[86] that 4 to $8 \mathrm{~g}$ of fructo-oligosaccharides and inulin/d are effective.

Nutrition assessment determines whether there is a need for nutritional support. If it is determined that there is insufficient intake relative to need (293× (bodyweight) $0.75 \mathrm{in} \mathrm{kJ} / \mathrm{ME}$ per day) then the (medical) cause needs to be eliminated where possible. A distinction is then made between hyporexia (decreased appetite, appetite is present but not optimal) and anorexia (complete loss of appetite). In hyporexia, a start can be made in improving the environment, palatability etc. In anorexia, a distinction must be made between patients with a functioning gastrointestinal tract (GI-tract) and patients with a non-functioning GI-tract or patients with excessive vomiting. Patients with a functioning GI-tract can be supported with the various types of enteral tubes. The choice depends on the expected duration of the anorexia. Patients with a non-functioning GI-tract or patients with excessive vomiting can be parentally supported. The choice of centrally (through a jugular catheter) or peripherally (through a peripheral catheter) depends on the expected duration of the dysfunction and/or vomiting and on what is possible for the clinic. If insufficient enteral support can be provided then partial parenteral support can be used. If the GI-tract is functioning again and/or excessive vomiting has ceased then the parenteral feeding can be phased out and replaced by enteral feeding (Figure 4).

\section{Conclusion}

After surgery or during serious illness several mechanisms disturb the nutritional situation resulting in delayed 


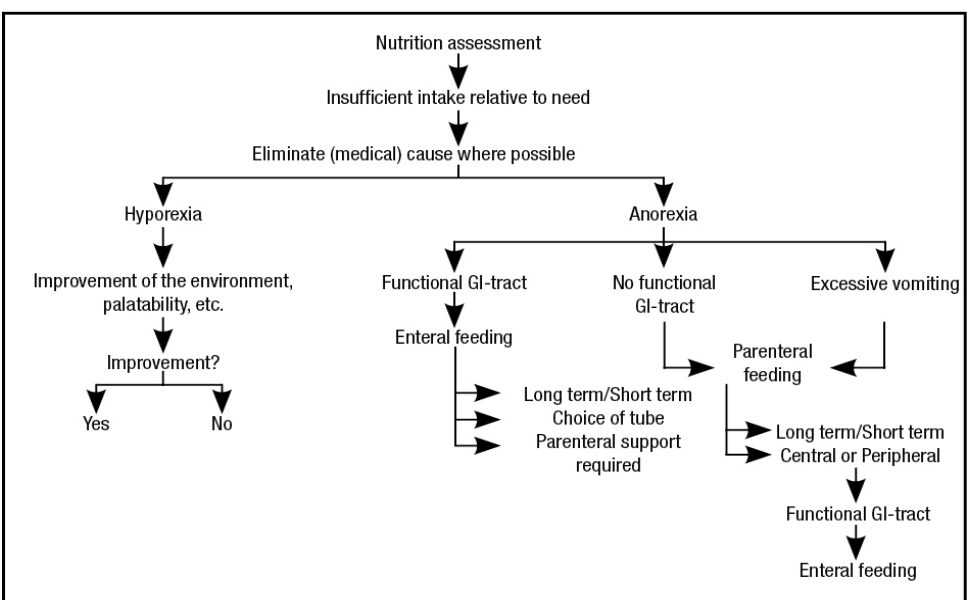

Nutrition assessment determines whether there is a need for nutritional support. If it is determined that there is insufficient intake relative to need (293× (bodyweight) $0.75 \mathrm{in} \mathrm{kJ} / \mathrm{ME}$ per day) then the (medical) cause needs to be eliminated where possible. A distinction is then made between hyporexia (decreased appetite, appetite is present but not optimal) and anorexia (complete loss of appetite). In hyporexia, a start can be made in improving the environment, palatability etc. In anorexia, a distinction must be made between patients with a functioning gastrointestinal tract (GI-tract) and patients with a non-functioning GI-tract or patients with excessive vomiting. Patients with a functioning GI-tract can be supported with the various types of enteral tubes. The choice depends on the expected duration of the anorexia. Patients with a non-functioning GI-tract or patients with excessive vomiting can be parentally supported. The choice of centrally (through a jugular catheter) or peripherally (through a peripheral catheter) depends on the expected duration of the dysfunction and/or vomiting and on what is possible for the clinic. If insufficient enteral support can be provided then partial parenteral support can be used. If the GI-tract is functioning again and/or excessive vomiting has ceased then the parenteral feeding can be phased out and replaced by enteral feeding.

\section{Figure 4. Decision tree for nutritional support.}

recovery. There is evidence that nutritional support early during the postoperative period or after onset of illness decreases the mortality rate and shortens the duration of hospitalization for dogs and cats. The preferred feeding route will depend on the condition of the patient. In case there are no clinical contraindications, patients should receive nutritional support, at least consistent with the resting energy requirement. Whereas the addition of food supplements containing nutrients belonging to several groups may be beneficial during healing and recovery from illness or surgery, further studies are needed to certify the favorable effects of these.

\section{References}

[1] Chambrier, C. and Sztark, F. (2012) Société Francophone de nutrition clinique, et métabolisme (SFNEP), Société française d'anesthésie et réanimation (SFAR). French clinical guidelines on perioperative nutrition. Update of the 1994 consensus conference on perioperative artificial nutrition for elective surgery in adults. Journal of Visceral Surgery, 149, e325-e336. http://dx.doi.org/10.1016/j.jviscsurg.2012.06.006

[2] Serón-Arbeloa, C., Puzo-Foncillas, J., Garcés-Gimenez, T., et al. (2011) A Retrospective Study about the Influence of Early Nutritional Support on Mortality and Nosocomial Infection in the Critical Care Setting. Clinical Nutrition, 30, 346-350. http://dx.doi.org/10.1016/j.clnu.2010.11.004

[3] Liu, D.T., Brown, D.C. and Silverstein, D.C. (2012) Early Nutritional Support Is Associated with Decreased Length of Hospitalization in Dogs with Septic Peritonitis: A Retrospective Study of 45 Cases (2000-2009). Journal of Veterinary Emergency and Critical Care, 22, 453-459. http://dx.doi.org/10.1111/j.1476-4431.2012.00771.x

[4] Chung, C.K., Whitney, R., Thompson, C.M., et al. (2013) Experience with an Enteral-Based Nutritional Support Regimen in Critically Ill Trauma Patients. Journal of the American College of Surgeons, 217, 1108-1117. http://dx.doi.org/10.1016/j.jamcollsurg.2013.08.006

[5] Saker, K.E. and Remillard, R.L. (2010) Critical Care Nutrition and Enteral-Assisted Feeding. In: Hand, M.S., Ed., Small Animal Clinical Nutrition, 5th Edition, Mark Morris Institute, Topeka, 439-476.

[6] Daley, B.J. and Bistrian, B.R. (1994) Nutritional Assessment. In: Zaloga, G.P., Ed., Nutrition in Critical Care, St Louis, Mosby, 9-33. 
[7] Walton, R.S., Wingfield, W.E. and Ogilvie, G.K. (1996) Energy Expenditure in 104 Postoperative and Traumatically Injured Dogs with Indirect Calorimetry. Journal of Veterinary Emergency and Critical Care, 6, 71-79. http://dx.doi.org/10.1111/j.1476-4431.1996.tb00035.x

[8] Desborough, J.P. (2000) The Stress Response to Trauma and Surgery. British Journal of Anaesthesia, 85, 109-117. http://dx.doi.org/10.1093/bja/85.1.109

[9] Desborough, J.P. and Hall, G.M. (1993) Endocrine Response to Surgery. Anesthesia Review, 10, 131-148.

[10] Otani, J. (2003) Feeding Tube Practices before and after Gastrointestinal Surgery. Infusion Therapy News, 2, 3-5.

[11] Yoshikawa, K. (1996) Feeding Tube Techniques and Carbohydrate Metabolism. Journal of Experimental \& Clinical Medicine, Special Issue, 9-14.

[12] WSAVA Global Nutrition Committee (2013) Feeding Guide for Hospitalized Dogs and Cats. www.wsava.org/sites/default/files/hospitalized\%20patient\%20feeding\%20guide.pdf

[13] Larsen, J.A. and Perea, S.C. (2011) Enteral Nutrition and Tube Feeding and Parenteral Nutrition. In: Fascetti, A.J. and Delaney, S.J., Eds., Applied Veterinary Clinical Nutrition, West Sussex, Blackwell, Chichester, 329-373.

[14] Seike, J., Tangoku, A., Yuas, Y., Okitsu, H., Kawakami, Y. and Sumitomo, M. (2011) The Effect of Nutritional Support on the Immune Function in the Acute Postoperative Period after Esophageal Cancer Surgery: Total Parenteral Nutrition versus Enteral Nutrition. The Journal of Medical Investigation, 58, 75-80. http://dx.doi.org/10.2152/jmi.58.75

[15] Okuma, T. (2007) Clinical Nutrition in Keywords: Enteral Tube Feeding. Nutrition Society, 66, 299-306.

[16] Omata, J., Fukatsu, K., Maeshima, Y., Moriya, T., Murakoshi, S., Noguchi, M., Okamoto, K., Fukazawa, S., Saitoh, D., Mochizuki, H., Yamamoto, J. and Hase, K. (2009) Enteral Nutrition Rapidly Reverses Total Parenteral Nutrition-Induced Impairment of Hepatic Immunity in a Murine Model. Clinical Nutrition, 28, 668-673. http://dx.doi.org/10.1016/j.clnu.2009.05.015

[17] Delaney, S.J. (2006) Management of Anorexia in Dogs and Cats. Veterinary Clinics of North America: Small Animal Practice, 36, 1243-1249. http://dx.doi.org/10.1016/j.cvsm.2006.08.001

[18] Freeman, L.M. (2012) Cachexia and Sarcopenia: Emerging Syndromes of Importance in Dogs and Cats. Journal of Veterinary Internal Medicine, 26, 3-17. http://dx.doi.org/10.1111/j.1939-1676.2011.00838.x

[19] WSAVA Nutritional Assessment Guidelines Task Force Members (2011) WSAVA Nutritional Assessment Guidelines. Journal of Feline Medicine \& Surgery, 13, 516-525. http://dx.doi.org/10.1016/j.jfms.2011.05.009

[20] Remillard, L. (2002) Nutritional Support in Critical Care Patients. Veterinary Clinics of North America: Small Animal Practice, 32, 1145-1164. http://dx.doi.org/10.1016/S0195-5616(02)00050-5

[21] Vadurel, A. and Gogny, M. (1997) L’odorat du chien: Aspects physiologique set facteurs de variation (Sense of Smell in Dogs: Physiological Aspects and Factors of Variation). Point Veterinaire, 28, 1037-1044.

[22] Kienzle, E., Meyer, H. and Schnieder, R. (1991) Investigations on Palatability, Digestibility and Tolerance of Low Digestible Food Components in Cats. Journal of Nutrition, 121, S56-S57.

[23] Smith, J.C., Rashottea, M.E., Austina, T. and Griffin, R.W. (1984) Fine-Grained Measures of Dogs’ Eating Behavior in Single-Pan and Two-Pan Tests. Neuroscience \& Biobehavioral Reviews, 8, 243-251. http://dx.doi.org/10.1016/0149-7634(84)90048-4

[24] Stein, L.J. (2001) Chemosensory Insights. Petfood Industry 2001, 4-6.

[25] Thomson, D.M.H. (1986) The Meaning of Flavour. In: Birch, G.G. and Lindley, M.G., Eds., Developments in Food Flavours, Elsevier Applied Science, London, 1-21.

[26] Fukatsu, K. (2007) Bacterial Translocation and the Patient’s Condition. Journal of Japan Surgical Society, 108, 138142.

[27] Fukushima, R. (2007) Counteraction against Bacterial Translocation (1) the Nutrient Canal. ournal of Japan Surgical Society, 108, 206-210.

[28] Carlson, G.L. and Dark, P. (2010) Acute Intestinal Failure. Current Opinion in Critical Care, 16, 347-352. http://dx.doi.org/10.1097/MCC.0b013e328339fabe

[29] Nakamura, T. (2004) Nutrient Canal Management for ER and ICU Patients. Infusion Therapy News, 3, 3-5.

[30] Marks, S.L., Cook, A.K., Griffey, S., Kass, P.H. and Rogers, Q.R. (1997) Dietary Modulation of Methotrexate-Induced Enteritis in Cats. American Journal of Veterinary Research, 58, 989-996.

[31] Wells, C.L. and Erlandsen, S.L. (1996) Bacterial Translocation: Intestinal Epithelial Permeability. In: Rombeau, J.L. and Takala, J., Eds., Update in Intensive Care and Emergency Medicine: Gut Dysfunction in Critical Illness, SpringerVerlag, Berlin, 131-145. http://dx.doi.org/10.1007/978-3-642-80224-9_9

[32] MacFie, J. (2004) Current Status of Bacterial Translocation as a Cause of Surgical Sepsis. British Medical Bulletin, 71, 
1-11. http://dx.doi.org/10.1093/bmb/ldh029

[33] Kazantsev, G.B., Hecht, D.W., Rao, R., Fedorak, I.J., Gattuso, P., Thompson, K., Djuricin, G. and Prinz, R.A. (1994) Plasmid Labeling Confirms Bacterial Translocation in Pancreatitis. American Journal of Surgery, 167, 201-207. http://dx.doi.org/10.1016/0002-9610(94)90074-4

[34] Liu, Q., Djuricin, G., Nathan, C., Gattuso, P., Weinstein, R.A. and Prinz, R.A. (2000) The Effect of Interleukin-6 on Bacterial Translocation in Acute Canine Pancreatitis. International Journal of Gastrointestinal Cancer, 27, 157-165. http://dx.doi.org/10.1385/IJGC:27:2:157

[35] Gennari, R. and Alexander, J.W. (1996) Effects of Hyperoxia on Bacterial Translocation and Mortality during GutDerived Sepsis. JAMA Surgery, 131, 57-62. http://dx.doi.org/10.1001/archsurg.1996.01430130059010

[36] Winkler, K.P., Greenfield, C.L. and Schaeffer, D.J. (2003) Bacteremia and Bacterial Translocation in the Naturally Occurring Canine Gastric Dilatation-Volvulus Patient. Journal of the American Animal Hospital Association, 39, 361368.

[37] Wells, C.L., Maddaus, M.A. and Simmons, R.L. (1988) Proposed Mechanisms for the Translocation of Intestinal Bacteria. Clinical Infectious Diseases, 10, 958-979. http://dx.doi.org/10.1093/clinids/10.5.958

[38] Dahlinger, J., Marks, S.L. and Hirsh, D.C. (1997) Prevalence and Identity of Translocating Bacteria in Healthy Dogs. Journal of Veterinary Internal Medicine, 11, 319-322. http://dx.doi.org/10.1111/j.1939-1676.1997.tb00473.x

[39] Hullár, I., Fekete, S., Andrásofszky, E., Szöcs, Z. and Berkényi, T. (2001) Factors Influencing the Food Preferences of Cats. Journal of Animal Physiology and Animal Nutrition, 85, 205-211. http://dx.doi.org/10.1046/j.1439-0396.2001.00333.x

[40] Ohno, K. (2008) Clinical Adoption of Enteral Feeding-Nutritional Support for Severely Ill Patients: Enteral Feeding or Intravenous Nutrition. Proceedings of 29th Annual Meeting of Japan Society of Clinical Veterinary Medicine, Tokyo, 2008, 211-213.

[41] Hand, M.S., Thatcher, C.D., Remillard, R.L., Roudebush, P. and Novotny, B.J. (2011) Small Animal Clinical Nutrition. 5th Edition, Mark Morris Institute.

[42] Sachdeva, P., Kantor, S., Knight, L.C., Maurer, A.H., Fisher, R.S. and Parkman, H.P. (2013) Use of a High Caloric Liquid Meal as an Alternative to a Solid Meal for Gastric Emptying Scintigraphy. Digestive Diseases and Sciences, 58, 2001-2006. http://dx.doi.org/10.1007/s10620-013-2665-2

[43] Jiang, P., Josue, J., Li, X., Glaser, D., Li, W.H., Brand, J.G., Margolskee, R.F., Reed, D.R. and Beauchamp, G.K. (2012) Major Taste Loss in Carnivorous Mammals. Proceedings of the National Academy of Sciences of the United States of America, 109, 4956-4961. http://dx.doi.org/10.1073/pnas.1118360109

[44] Bower, R.H., Cerra, F.B., Bershadsky, B., et al. (1995) Early Enteral Feeding of a Formula (Impact Registered Trademark) Supplemented with Arginine, Nucleotides, and Fish Oil in Intensive Care Unit Patients: Results of a Multicenter, Prospective, Randomized, Clinical Trial. Critical Care Medicine, 23, 436-449. http://dx.doi.org/10.1097/00003246-199503000-00006

[45] Goffschlich, M.M., Jenkins, M., Warden, G.D., Baumer, T., Havens, P., Snook, J.T. and Alexander, J.W. (1990) Differential Effects of Three Dietary Regimens on Selected Outcome Variables in Burn Patients. JPEN Journal of Parenteral and Enteral Nutrition, 14, 225-236. http://dx.doi.org/10.1177/0148607190014003225

[46] Evoy, D., Lieberman, M.D., Fahey III, T.J. and Daly, J.M. (1998) Immunonutrition: The Role of Arginine. Nutrition, 14, 611-617. http://dx.doi.org/10.1016/S0899-9007(98)00005-7

[47] León, P., Redmond, H.P., Stein, T.P., Shou, J., Schluter, M.D., Kelly, C., Lanza-Jacoby, S. and Daly, J.M. (1991) Arginine Supplementation Improves Histone and Acute-Phase Protein Synthesis during Gram-Negative Sepsis in the Rat. JPEN Journal of Parenteral and Enteral Nutrition, 15, 503-508.

[48] Seifter, E., Rettura, G., Barbul, A. and Levenson, S.M. (1978) Arginine: An Essential Amino Acid for Injured Rats. Surgery, 84, 224-230.

[49] Pui, Y.M. and Fisher, H. (1979) Factorial Supplementation with Arginine and Glycine on Nitrogen Retention and Body Weight Gain in the Traumatized Rat. Journal of Nutrition, 109, 240-246.

[50] Duggan, C., Gannon, J. and Walker, W.A. (2002) Protective Nutrients and Functional Foods for the Gastrointestinal Tract. American Journal of Clinical Nutrition, 75, 789-808.

[51] Prins, H.A., Houdijk, A.P., van Lambalgen, A.A., Teerlink, T., Meijer, S., Thijs, L.G. and van Leeuwen, P.A.M. (1998) Paradoxical Changes in Organ Blood Flow after Arginase Infusion in the Non-Stressed Rat. Shock, 9, 422-427. http://dx.doi.org/10.1097/00024382-199806000-00006

[52] Campos, F.G., Waitzberg, D.L., Logulo, A.F., Mucerino, D.R. and Habr-Gama, A. (1996) The Role of Glutamine in Nutrition in Clinical Practice [in Portuguese]. Arquivos de Gastroenterologia, 33, 86-92.

[53] O’Flaherty, L. and Bouchier-Hayes, D.J. (1999) Immunonutrition and Surgical Practice. Proceedings of the Nutrition 
Society, 58, 831-837. http://dx.doi.org/10.1017/S0029665199001123

[54] Greenfield, J.R., Farooqi, I.S., Keogh, J.M., Henning, E., Habib, A.M., Blackwood, A., Reimann, F., Holst, J.J. and Gribble, F.M. (2009) Oral Glutamine Increases Circulating Glucagon-Like Peptide 1, Glucagon, and Insulin Concentrations in Lean, Obese, and Type 2 Diabetic Subjects. American Journal of Clinical Nutrition, 89, 106-113. http://dx.doi.org/10.3945/ajcn.2008.26362

[55] Houdijk, A.P., van Leeuwen, P.A., Teerlink, T., Flinkerbusch, E.L., Boermeester, M.A., Sauerwein, H.P. and Wesdorp, R.I.C. (1994) Glutamine-Enriched Enteral Diet Increases Renal Arginine Production. JPEN Journal of Parenteral and Enteral Nutrition, 18, 422-426. http://dx.doi.org/10.1177/0148607194018005422

[56] Klimberg, V.S., Salloum, R.M., Kasper, M., et al. (1990) Oral Glutamine Accelerates Healing of the Small Intestine and Improves Outcome after Whole Abdominal Radiation. JAMA Surgery, 125, 1040-1045. http://dx.doi.org/10.1001/archsurg.1990.01410200104017

[57] Kozar, R.A., Schultz, S.G., Bick, R.J., Poindexter, B.J., DeSoignie, R. and Moore, F.A. (2004) Enteral Glutamine but Not Alanine Maintains Small Bowel Barrier Function after Ischemia/Reperfusion Injury in Rats. Shock, 21, 433-437. http://dx.doi.org/10.1097/00024382-200405000-00006

[58] Souba, W.W., Roughneen, P.T., Goldwater, D.L., Williams, J.C. and Rowlands, B.J. (1987) Postoperative Alterations in Interorgan Glutamine Exchange in Enterectomized Dogs. Journal of Surgical Research, 42, 117-125. http://dx.doi.org/10.1016/0022-4804(87)90108-9

[59] Wischmeyer, P.E. (2006) Glutamine: Role in Gut Protection in Critical Illness. Current Opinion in Clinical Nutrition \& Metabolic Care, 9, 607-612. http://dx.doi.org/10.1097/01.mco.0000241672.09676.03

[60] O’Dwyer, S.T., Smith, R.J., Hwang, T.L. and Wilmore, D.W. (1989) Maintenance of Small Bowel Mucosa with Glutamine-Enriched Parenteral Nutrition. JPEN Journal of Parenteral and Enteral Nutrition, 13, 579-585. http://dx.doi.org/10.1177/0148607189013006579

[61] Ligthart-Melis, G.C., van de Poll, M.C.G., Dejong, C.H.C., Boelens, P.G., Deutz, N.E.P. and van Leeuwen, P.A.M. (2007) The Route of Administration (Enteral or Parenteral) Affects the Conversion of Isotopically Labeled L-[2- $\left.{ }^{15} \mathrm{~N}\right]$ Glutamine into Citrulline and Arginine in Humans. JPEN Journal of Parenteral and Enteral Nutrition, 31, 343-350. http://dx.doi.org/10.1177/0148607107031005343

[62] Yang, R., Martin-Hawver, L., Woodall, C., Thomas, A., Qureshi, N., Morrison, D. and Van Way, C. (2007) Administration of Glutamine after Hemorrhagic Shock Restores Cellular Energy, Reduces Cell Apoptosis and Damage, and Increases Survival. JPEN Journal of Parenteral and Enteral Nutrition, 31, 94-100. http://dx.doi.org/10.1177/014860710703100294

[63] Redmond, H.P., Stapleton, P.P., Neary, P. and Bouchier-Hayes, D. (1998) Immunonutrition: The Role of Taurine. Nutrition, 14, 599-604. http://dx.doi.org/10.1016/S0899-9007(98)00097-5

[64] Lee, J.H., Jarreau, T., Prasad, A., Lavie, C., O’Keefe, J. and Ventura, H. (2011) Nutritional Assessment in Heart Failure Patients. Congestive Heart Failure, 17, 199-203. http://dx.doi.org/10.1111/j.1751-7133.2011.00239.x

[65] Wójcik, O.P., Koenig, K.L., Zeleniuch-Jacquotte, A., Costa, M. and Chen, Y. (2010) The Potential Protective Effects of Taurine on Coronary Heart Disease. Atherosclerosis, 208, 19-25. http://dx.doi.org/10.1016/j.atherosclerosis.2009.06.002

[66] Sanderson, S.L. (2006) Taurine and Carnitine in Canine Cardiomyopathy. Veterinary Clinics of North America: Small Animal Practice, 36, 1325-1343. http://dx.doi.org/10.1016/j.cvsm.2006.08.010

[67] Lenox, C.E. and Bauer, J.E. (2013) Potential Adverse Effects of Omega-3 Fatty Acids in Dogs and Cats. Journal of Veterinary Internal Medicine, 27, 217-226. http://dx.doi.org/10.1111/jvim.12033

[68] Johnson III, J.A., Griswold, J.A. and Muakkassa, F.F. (1993) Essential Fatty Acids Influence Survival in Sepsis. Journal of Trauma, 35, 128-131. http://dx.doi.org/10.1097/00005373-199307000-00020

[69] Kollman, K.A., Lein, E.L. and Vanderhoof, J.A. (1999) Dietary Lipids Influence Adaptation after Massive Bowel Resection. Journal of Pediatric Gastroenterology \& Nutrition, 28, 41-45. http://dx.doi.org/10.1097/00005176-199901000-00011

[70] Freeman, L.M. (1998) Interventional Nutrition for Cardiac Disease. Clinical Techniques in Small Animal Practice, 13, 232-237. http://dx.doi.org/10.1016/S1096-2867(98)80008-X

[71] Watson, T.D.G. (1998) Diet and Skin Disease in Dogs and Cats. Journal of Nutrition, 128, 2783S-2789S.

[72] Corbee, R.J., Barnier, M.M.C., Tryfonidou, M.A., et al. (2013) The Effect of Dietary Long-Chain Omega-3 Fatty Acids Supplementation on Owner's Perception of Behavior and Locomotion in Cats with Naturally Occurring Osteoarthritis. Journal of Animal Physiology and Animal Nutritionr, 97, 846-853.

[73] Roush, J.K., Dodd, C.E., Fritsch, D.A., et al. (2010) Multicenter Veterinary Practice Assessment of the Effects of Omega-3 Fatty Acids on Osteoarthritis in Dogs. Journal of the American Veterinary Medical Association, 236, 59-66. http://dx.doi.org/10.2460/javma.236.1.59 
[74] Atasoy, B.M., Deniz, M., Dane, F., Özen, Z., Turan, P., Ercan, F., Çerikçioğlu, N., Aral, C., Akgün, Z., Abacioğlu, U. and Yeğen, B.Ç. (2010) Prophylactic Feeding with Immune-Enhanced Diet Ameliorates Chemoradiation-Induced Gastrointestinal Injury in Rats. International Journal of Radiation Biology, 86, 867-879.

[75] Lasztity, N., Hamvas, J., Biro, L., Németh, É., Marosvölgyi, T., Decsi, T., Pap, Á. And Antal, M. (2005) Effect of Enterally Administered n-3 Polyunsaturated Fatty Acids in Acute Pancreatitis: A Prospective Randomized Clinical Trial. Clinical Nutrition, 24, 198-205. http://dx.doi.org/10.1016/j.clnu.2004.12.008

[76] Smith, C.E., Freeman, L.M., Rush, J.E., Cunningham, S.M. and Biourge, V. (2007) Omega-3 Fatty Acids in Boxer Dogs with Arrhythmogenic Right Ventricular Cardiomyopathy. Journal of Veterinary Internal Medicine, 21, $265-273$. http://dx.doi.org/10.1111/j.1939-1676.2007.tb02959.x

[77] Freeman, L.M. (2010) Beneficial Effects of Omega-3 Fatty Acids in Cardiovascular Disease. Journal of Small Animal Practice, 51, 462-470. http://dx.doi.org/10.1111/j.1748-5827.2010.00968.x

[78] Brown, S.A., Brown, C.A., Crowell, W.A., Barsanti, J.A., Allen, T., Cowell, C. and Finco, D.R. (1998) Beneficial Effects of Chronic Administration of Dietary Omega-3 Polyunsaturated Fatty Acids in Dogs with Renal Insufficiency. Journal of Laboratory and Clinical Medicine, 131, 447-455. http://dx.doi.org/10.1016/S0022-2143(98)90146-9

[79] Trepanier, L. (2009) Idiopathic Inflammatory Bowel Disease in Cats. Rational Treatment Selection. Journal of Feline Medicine \& Surgery, 11, 32-38. http://dx.doi.org/10.1016/j.jfms.2008.11.011

[80] Bauer, J.E. (2011) Therapeutic Use of Fish Oils in Companion Animals. Journal of the American Veterinary Medical Association, 239, 1441-1451. http://dx.doi.org/10.2460/javma.239.11.1441

[81] Gibson, G.R., Beatty, E.R., Wang, X. and Cummings, J.H. (1995) Selective Stimulation of Bifidobacteria in the Human Colon by Oligofructose and Inulin. Gastroenterology, 108, 975-982. http://dx.doi.org/10.1016/0016-5085(95)90192-2

[82] Jackson, K.G., Taylor, G.R., Clohessy, A.M. and Williams, C.M. (1999) The Effect of the Daily Intake of Inulin on Fasting Lipid, Insulin and Glucose Concentrations in Middle-Aged Men and Women. British Journal of Nutrition, 82, 23-30. http://dx.doi.org/10.1017/S0007114599001087

[83] St-Onge, M.P. and Jones, P.J. (2002) Physiological Effects of Medium-Chain Triglycerides: Potential Agents in the Prevention of Obesity. Journal of Nutrition, 132, 329-332.

[84] Kleessen, B., Sykura, B., Zunft, H.J. and Blaut, M. (1997) Effects of Inulin and Lactose on Fecal Microflora, Microbial Activity and Bowel Habit in Elderly Constipated Persons. American Journal of Clinical Nutrition, 65, 1397-1402.

[85] Roberfroid, M.B. and Delzeene, N.M. (1998) Dietary Fructans. Annual Review of Nutrition, 18, 117-143. http://dx.doi.org/10.1146/annurev.nutr.18.1.117

[86] Roberfroid, M. (1993) Dietary Fiber, Inulin, and Oligofructose: A Review Comparing Their Physiological Effects. Critical Reviews in Food Science and Nutrition, 33, 103-148.

Parts of this manuscript has been published in Dutch Corbee, R.J. and van Kerkhoven, W. (2012) Nutritionele ondersteuning van de opgenomen patiënt. Tijdschrift voor Diergeneeskunde, 137, 384-390.

[A] Prescription diet a/d, Hill’s Pet Nutrition Inc, Topeka, Kan.

[B] Royal Canin Veterinary Diet Recovery RS, Royal Canin USA Inc., St Charles, Mo.

[C] Eukanuba Max Cal, Iams, P\&G, Henderson, NC.

[D] Viyo Recuperation, Viyo International N.V., Antwerp, Belgium.

[E] Krizova, I., Martin, J. and Saker, K.E. Glutamine-Enhanced Shock Fluids Diminish Physiological Consequences of Hemorrhagic Shock. Proceedings. 4th Annu Am Acad Vet Nutr Clin Nutr Res Symp 2004. 